\title{
Comparação mensal, sazonal e anual de métodos de estimativas da evapotranspiração de referência para Juazeiro-BA e Petrolina-PE
}

\author{
Monthly, seasonal and annual comparison of methods for reference evapotranspiration \\ estimates to Juazeiro-BA and Petrolina-PE
}

\author{
CABRAL JÚNIOR ${ }^{1}$, J. B.; SILVA ${ }^{2}$, C. M. S.; ALMEIDA ${ }^{3}$, H. A. \\ jorio.cabral@gmail.com;
}

\begin{abstract}
Resumo
A Evapotranspiração de referência $\left(\mathrm{ET}_{0}\right)$ além de ser um importante indicador climático é também um indicativo da demanda de água para a atmosfera, cujo conhecimento fornece subsídios para o manejo e gestão dos recursos hídricos, especialmente nas atividades agrícolas. O objetivo principal deste trabalho é o de comparar a $\mathrm{ET}_{0}$ estimada por diferentes métodos para Juazeiro, BA $\left(09^{\circ} 24^{\prime} \mathrm{S}\right.$; $40^{\circ} 26^{\prime} \mathrm{W}$ e $\left.375,5 \mathrm{~m}\right)$ e Petrolina, PE $\left(09^{\circ} 09^{\prime} \mathrm{S}\right.$, $40^{\circ} 22^{\prime} \mathrm{W}$ e $\left.376 \mathrm{~m}\right)$. De posse dos dados meteorológicos diários, disponibilizados pela EMBRAPA Semiárido, no período de 01.01.1976 a 31.12.2014, estimou-se a $\mathrm{ET}_{0}$ diária utilizando-se o método padrão de Penman-Monteith (ET $\mathrm{E}_{0} \mathrm{PM}$ ). Outros métodos de estimativas (mais simplificados) foram estimados e comparados à $\mathrm{ET}_{0} \mathrm{PM}$, a citar: Radiação Solar (ET $\left.\mathrm{ES}_{0}\right)$ Linacre $\left(\mathrm{ET}_{0} \mathrm{~L}\right)$, Hargreaves e Samani (ET $\mathrm{ESS}_{0}$ e o método do Tanque Classe A (ET $\mathrm{ETCA}_{0}$. O teste de média t de Student foi aplicado para averiguar se há diferença significativa entre as médias de estimativas da $E_{0}$. O coeficiente de correlação (r) e estatísticas de Willmott et al. (1985) foram utilizadas para avaliar o índice de concordância e de desempenho. Em termos comparativos o método de melhor concordância com a $\mathrm{ET}_{0} \mathrm{PM}$ foi a $\mathrm{ET}_{0} \mathrm{RS}$ com desempenho muito bom, nas duas localidades, seguido pelo método da $\mathrm{ET}_{0} \mathrm{~L}$ com desempenho bom (Juazeiro) e mediano (Petrolina). $\mathrm{A} \mathrm{ET}_{0} \mathrm{HS}$ obteve o pior desempenho (péssimo), para as duas localidades. Conclui-se, para as localidades analisadas, que na ausência de dados meteorológicos para estimar a $\mathrm{ET}_{0}$ pelo método padrão poder-se-á estimar a $\mathrm{ET}_{0}$ através da regressão linear simples utilizando como variável independente a $\mathrm{ET}_{0} \mathrm{RS}$ ou a $\mathrm{ET}_{0} \mathrm{~L}$.
\end{abstract}

Palavras-chave: Agroclimatologia, Nordeste, Evapotranspiração, Penman-Monteith.

\begin{abstract}
The reference Evapotranspiration $\left(\mathrm{ET}_{0}\right)$ in addition to being an important climate indicator is also indicative of the demand of water to the atmosphere, of which knowledge provides subsidies for the handling and management of water resources, especially in agricultural activities. The main objective of this work is to compare the $\mathrm{ET}_{0}$ estimated by different methods to Juazeiro, BA $\left(09^{\circ} 24^{\prime} \mathrm{S} ; 40^{\circ} 26^{\prime} \mathrm{W}\right.$ and 375 feet) and Petrolina, PE $\left(09^{\circ} 09^{\prime} \mathrm{S}, 40^{\circ} 22^{\prime} \mathrm{W}\right.$ and $\left.376 \mathrm{~m}\right)$. Possession of daily meteorological data provided by EMBRAPA Semi-arid, in the period of the 01.01.1976 31.12.2014, estimated the daily $\mathrm{ET}_{0}$ using the default method of Penman-Monteith $\left(\mathrm{ET}_{0} \mathrm{PM}\right)$. Other methods of estimates (more streamlined) were estimated and compared to $\mathrm{ET}_{0} \mathrm{PM}$, quoting: Solar Radiation $\left(\mathrm{ET}_{0} \mathrm{RS}\right)$, Linacre $\left(\mathrm{ET}_{0} \mathrm{~L}\right)$, Hargreaves and Samani $\left(\mathrm{ET}_{0} \mathrm{HS}\right)$ and the method of the tank class (ET $\left.\mathrm{ET}_{0} \mathrm{TCA}\right)$. The average Student's t test was applied to find out whether there are significant differences between the estimates of the $\mathrm{ET}_{0}$. The correlation coefficient (r) and statistics of Willmott et al. (1985) were used to evaluate the agreement and performance index. In comparative terms the best correlation method with the $\mathrm{ET}_{0} \mathrm{PM}$ were the $\mathrm{ET}_{0} \mathrm{RS}$ with very good performance, in both locations, followed by the $\mathrm{ET}_{0} \mathrm{~L}$ with good performance (Juazeiro) and median (Petrolina). The $\mathrm{ET}_{0} \mathrm{HS}$ obtained the worst performance (bad) for both locations. It is therefore concluded to localities analyzed, that in the absence of weather data to estimate the $\mathrm{ET}_{0}$ by the default method can estimate the $\mathrm{ET}_{0}$ by simple linear regression using as independent variable the $\mathrm{ET}_{0} \mathrm{RS}$ or the $\mathrm{ET}_{0} \mathrm{~L}$.
\end{abstract}

Keywords: Agroclimatology, Northeast, Evapotranspiration, Penman-Monteith.

\section{INTRODUÇÃO}

O Brasil é o segundo maior exportador de produtos agrícolas no mundo (OCDE-FAO, 2014). Especialmente, na região do Semiárido do Nordeste do Brasil (SANEB), as

\footnotetext{
${ }^{1}$ Jório Bezerra Cabral Júnior, Centro de Ciências Exatas e da Terra, Universidade Federal do Rio Grande do Norte, Natal-RN, Brasil.

${ }^{2}$ Claúdio Moisés Santos e Silva, Departamento de Ciências Atmosféricas e Climáticas, Universidade Federal do Rio Grande do Norte, Natal-RN, Brasil
}

${ }^{3}$ Hermes Alves de Almeida, Departamento de Geografia, Universidade Estadual da Paraíba, Campina Grande-PB,, Brasil. 
microrregiões de Juazeiro (Bahia) e de Petrolina (Pernambuco) têm crescido e ganhado destaque na agricultura irrigada, desde a sua criação, no ano de 1965. Nesse ano foram recomendadas pela Food and Agriculture Organization of the United Nations (FAO) como regiões promissoras à implementação da agricultura irrigada (ALBUQUERQUE e CÂNDIDO, 2013).

Neste sentido são destaques os municípios de Juazeiro e Petrolina, por serem centros de um polo irrigado (CORREIA et al., 2001); com o maior exemplo de desenvolvimento agrícola em áreas irrigadas da região do SANEB (LACERDA \& LACERDA, 2004) e é por causa da técnica de irrigação que se desenvolvem consideravelmente (TEIXEIRA, 2010).

O que ainda limita a produção agrícola no SANEB é a escassez de recursos hídricos, pois segundo Almeida e Silva (2008) as chuvas são irregulares no espaço e no tempo. Segundo dados da Articulação do Semiárido (ASA, 2014), além dessa característica, a quantidade de chuva anual é menor do que a evapotranspiração de referência $\left(\mathrm{ET}_{0}\right)$, portanto, há predominância de déficit hídrico no solo e necessidade de um eficiente manejo e gestão da água para agricultura nessa região (SILVA, 2007; CUNHA et al., 2015).

$\mathrm{O}$ conhecimento e aplicações relacionados ao comportamento da $\mathrm{ET}_{0}$ é de grande importância para planejamento dos recursos hídricos, manejo de irrigação e produção agrícola (HATCH et al., 1999; HAN e HU, 2012; SHAN et al., 2015). Nam et al. (2015) e Jhajharia et al. (2015) afirmaram que a $\mathrm{ET}_{0}$ é um importante e fundamental parâmetro na determinação da demanda de água para irrigação de culturas agrícolas.

De acordo com Grismer et al. (2002), existe cerca de cinquenta métodos para a estimativa da $\mathrm{ET}_{0}$, os quais exigem informações meteorológicas distintas e, portanto, produzem frequentemente, resultados inconsistentes. Desde os anos 1990 a FAO estabeleceu o método de Penman-Monteith como sendo o padrão. O critério para tornar este método como o padrão foi em função de ser o mais preciso em condições diversas.

Diversos métodos de estimativa de $\mathrm{ET}_{0}$ têm sido aplicados, porém é fundamental saber a sua adequabilidade para cada região. Por esse propósito, Oliveira et al. (2001) sugerem o cuidado em avaliar com extrema cautela o grau de exatidão de cada método de estimativa antes de utilizá-lo para nova condição.

O objetivo principal neste trabalho foi o de comparar diferentes métodos de estimativas da $\mathrm{ET}_{0}$, nas escalas mensal, sazonal e anual, obtendo-se como referência o método padrão de Penman-Monteith, para os perímetros irrigados de Juazeiro e Petrolina. 


\section{MATERIAL E MÉTODOS}

\section{1. Área de estudo}

A área de estudo, observada na Figura 1, compreende dois perímetros de irrigação. O primeiro é localizado na microrregião de Juazeiro-BA (perímetro irrigado de Mandacaru), (09 24' 36' 'Sul, 40 26' 36' Oeste e 375,5 m). O segundo na microrregião de Petrolina-PE (perímetro irrigado de Bebedouro) (09 09' 00’' Sul, 40²2' Oeste e 376 m). As estações meteorológicas são separadas por uma distância de 30 km (TEIXEIRA, 2010).

As temperaturas médias anuais em Petrolina e Juazeiro são: $24^{\circ} \mathrm{C}$ e $26^{\circ} \mathrm{C}$, respectivamente). A classificação climática através do método de Köppen da região é do tipo BSh, ou seja, clima semiárido com temperatura média do ar no mês mais frio superior a $18^{\circ} \mathrm{C}$ e média de precipitação acumulada anual inferior a 700 mm (TEIXEIRA, 2009).

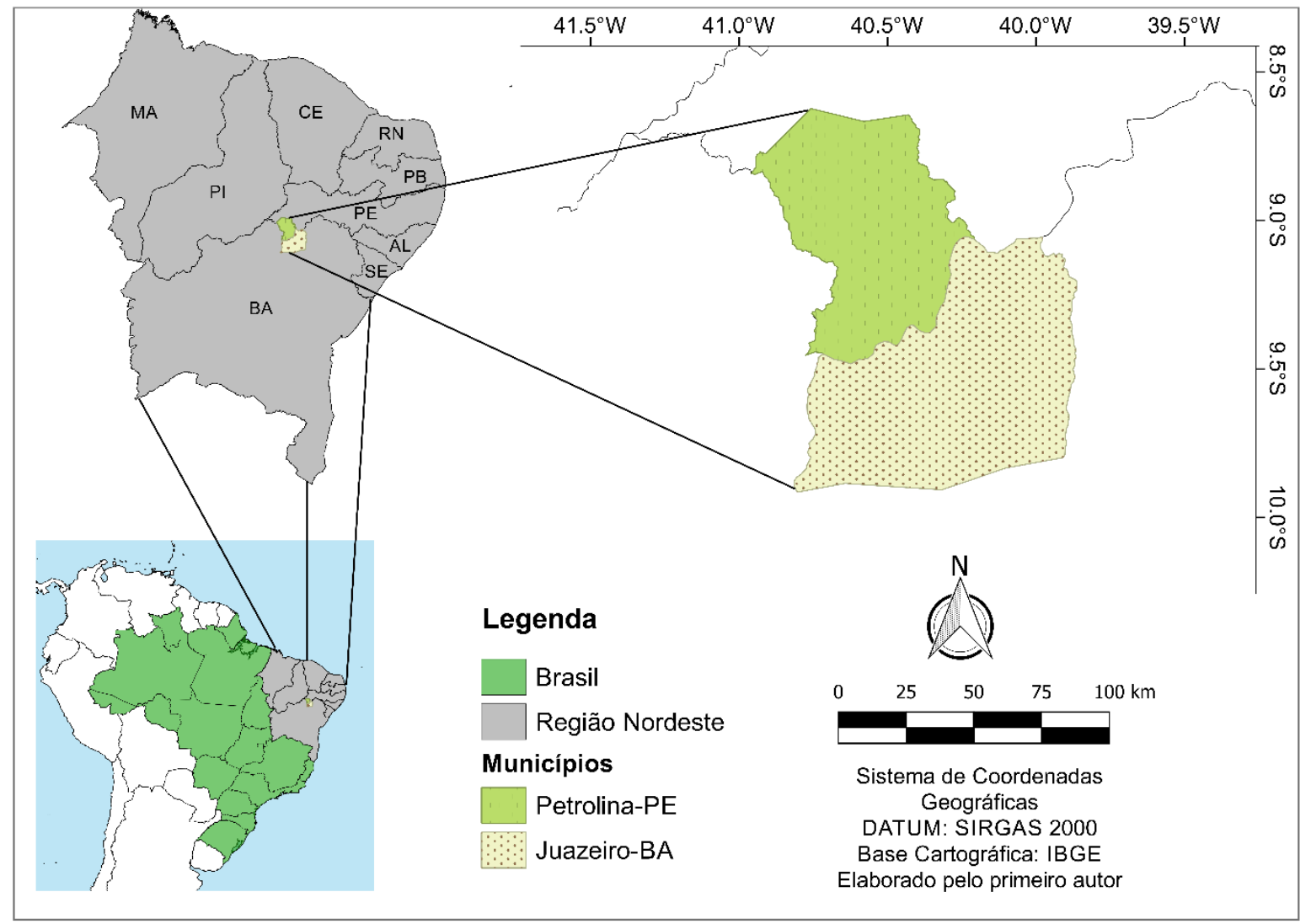

Figura 1. Localização dos municípios em que estão inseridos os perímetros irrigados de Juazeiro, BA e Petrolina, PE, ambos, na região do Nordeste brasileiro. Fonte: Elaborado pelo autor.

\subsection{Dados}

Utilizaram-se séries de dados meteorológicos diários coletados durante o período de 01.01.1976 a 31.12.2014 disponibilizado pela EMBRAPA Semiárido. Realizou-se um 
preenchimento de falhas através da técnica Multivariate Imputation by Chained Equatoins (MICE) (VAN BUUREN, 2011). Essa técnica é utilizada para preenchimento de dados faltantes em séries históricas, faltas essas causadas por motivos diversos, como falha no instrumento ou problemas nas estações meteorológicas (COSTA et al., 2012).

O MICE consiste em gerar imputações múltiplas para dados multivariados através do método Gibbs Sampling. O algoritmo imputa dados em uma coluna incompleta (coluna alvo) baseando-se em outras colunas do banco de dados. Cada coluna incompleta deve ser considerada como uma coluna-alvo e tem seus próprios preditores. O conjunto de preditores consiste de todas as outras colunas do banco de dados. Utilizaram-se como variáveis preditoras aquelas que obtiveram maiores correlações com a variável do dado faltante. Os métodos de imputação múltipla utilizados nessa análise foram PMM - Predictive Mean Matching (Numeric).

\subsection{ET $_{0}$ pelo método padrão de Penman-Monteith FAO-56 ( $\left.E T_{0} P M\right)$}

A ET 0 foi calculada pelo método padrão Penman-Monteith FAO-56 (ALLEN et al., 1998), definida como a taxa de evapotranspiração de uma cultura hipotética, com altura de $0,12 \mathrm{~m}$, resistência do dossel de $70 \mathrm{~s} . \mathrm{m}^{-1}$ e albedo de $23 \%$, conforme equação 1:

$$
E T_{0} P M=\frac{0,408 \cdot \Delta\left(R_{n}-G\right)+\gamma\left(\frac{900 \cdot U_{2}}{T_{\text {med }}+273}\right)\left(e_{s}-e_{a}\right)}{\Delta+\gamma \cdot\left(1+0,34 U_{2}\right)}
$$

em que $R_{n}$ é o saldo do balanço de radiação solar incidente em ondas curtas e a radiação terrestre, emitida em ondas longas; $\mathrm{G}$ é a densidade de fluxo de calor do solo (tanto em $\mathrm{MJ} \mathrm{m}^{-}$ $\left.{ }^{2} \mathrm{~d}^{-1}\right) ;-\mathrm{T}_{\text {med }}$ é a temperatura média diária do ar $\left({ }^{\circ} \mathrm{C}\right) ; \mathrm{U}_{2}$ é a velocidade média do vento, do dia

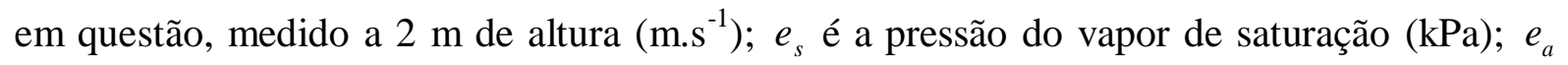
representa a pressão de vapor real $(\mathrm{kPa}) ; e_{s}-e_{a}$ é o déficit de pressão de vapor $(\mathrm{kPa}) ; \Delta$ é a inclinação da curva de pressão de vapor $\left(\mathrm{KPa}^{\circ} \mathrm{C}^{-1}\right) ; \gamma$ é a constante psicrométrica $\left(\mathrm{kPa}^{\circ} \mathrm{C}^{-1}\right)$.

\section{4. $\mathrm{ET}_{0}$ pelo método Hargreaves e Samani (1985) $\left(E T_{0} H S\right)$}

O cálculo para estimar a $E T_{0} H S$ é dado por: 


$$
E T_{0} H S=0,0023 \cdot Q_{0} \cdot(t m a ́ x-t m i n)^{0,5} \cdot(t m e d+17,8)
$$

Sendo: tmed - temperatura média diária do ar $\left({ }^{\circ} \mathrm{C}\right)$;

tmáx - temperatura máxima diária do ar $\left({ }^{\circ} \mathrm{C}\right)$;

tmin - temperatura mínima diária do $\operatorname{ar}\left({ }^{\circ} \mathrm{C}\right)$;

$Q_{0}$ - radiação solar extraterrestre ( $\mathrm{mm}$ de evaporação equivalente).

A $Q_{0}$ pode ser obtida por meio de equação descrita por Vianello e Alves (2012).

\section{5. $\mathrm{ET}_{0}$ pelo método Tanque Classe $\mathrm{A}\left(E T_{0} T C A\right)$}

A evaporação deste método é medida através de um tanque de material galvanizado, cujo diâmetro é de $120,7 \mathrm{~cm}$, altura de $25 \mathrm{~cm}$, a $15 \mathrm{~cm}$ de distância do solo e com bordadura (distância) do tanque, conforme mostra a Figura 7, padrões estes recomendados pela FAO (ALLEN et al., 1998).

Para a conversão da evaporação em evapotranspiração de referência, utilizou-se a equação:

$$
E T_{0} T C A=E C A(K p)
$$

Sendo: $E C A$ - a lâmina da evaporação do tanque "Classe A" (mm.d $\left.{ }^{-1}\right)$;

$K p$ - coeficiente de conversão da evaporação (mudar espaçamento) do tanque "Classe A" em evapotranspiração de referência ( $K p$, admensional).

Neste estudo optou-se por utilizar o Kp proposto por Snyder (1992) dado por:

$$
K p=0,482+0,24 n(F)-0,000376\left(U_{2}\right)+0,0045(U R)
$$

Sendo: $F$ - tamanho da bordadura do Tanque ( $F=10 \mathrm{~m}$, para as estações estudadas);

$U_{2}$ - velocidade média diária do vento $\left(\mathrm{km} \cdot \mathrm{dia}^{-1}\right)$;

$U R$ - Umidade Relativa média do ar (\%).

Outro Kp utilizado foi o proposto por Pereira et al. (1995) $\left(E T_{0} T C A_{-} P\right)$ expresso por: 


$$
K p=\frac{0,84(\Delta+\gamma)}{\left[\Delta+\gamma\left(1+\frac{r_{c}}{r_{a}}\right)\right]}
$$

Sendo: $\Delta$ e $\gamma$ - Definidos na equação da $E T o P M$;

$\frac{r_{c}}{r_{a}}$ - é a relação entre a resistência do dossel da grama à difusão do vapor d'água $\left(r_{c}\right)$ e a resistência aerodinâmica para a troca do vapor d'água de uma superfície evaporante $\left(r_{a}\right)$, dados por uma relação empírica com a velocidade do vento, adotado pela FAO (ALLEN et al., 1998):

$$
\frac{r_{c}}{r_{a}}=0,34 U_{2}
$$

\section{6. $\mathbf{E T}_{0}$ pelo método da Radiação Solar ( $\left.E T_{0} R S\right)$}

A estimativa da EToRS é calculada de acordo com a seguinte equação:

$$
E T_{0} R S=c \times W \times Q g
$$

Em que: c - constante em função da $U R(\%)$ e da $U_{2}\left(\mathrm{~m}_{\mathrm{s}} \mathrm{s}^{-1}\right)$, expresso por:

$$
\begin{aligned}
& c=1,0656-0,0012795(U R)+0,044953\left(U_{2}\right)- \\
& 0,00020033(U R)\left(U_{2}\right)-0,000031508(U R)^{2}- \\
& 0,0011026\left(U_{2}^{2}\right)
\end{aligned}
$$

$W$ - fator de ponderação da temperatura, dado por:

$$
W=0,0483+0,01(\text { tar })
$$

Em que: $t a r$ - temperatura do ar média diária $\left({ }^{\circ} \mathrm{C}\right)$;

$Q g$ - radiação solar global diária $\left(\mathrm{mm} \cdot \mathrm{dia}^{-1}\right)$;

$U_{2}$ - velocidade média do vento a 2 metros de altura $\left(\mathrm{m} . \mathrm{s}^{-1}\right)$;

$U R$ - umidade relativa do ar (\%). 


\section{7. $\mathbf{E T}_{0}$ pelo método de Linacre (1977) ( $\left.E T_{0} L\right)$.}

A estimativa da EToL é calculada de acordo com a seguinte equação:

$$
E T o L=\frac{\frac{J(t+0,006 h)}{100-\phi}+15(t-t o)}{80-t}
$$

Sendo: $J$ - igual a 500 para superfícies cobertas com vegetação e 700 com água-livre;

$t$ - temperatura média mensal $\left(\mathrm{em},{ }^{\circ} \mathrm{C}\right)$;

$h$ - altitude do local (em metros);

$t_{o^{-}}$temperatura média mensal do ponto de orvalho, $\left(\mathrm{em}{ }^{\circ} \mathrm{C}\right)$;

$\phi$ - latitude do local em graus (módulo).

A temperatura do ponto de orvalho (to ) foi determinada pela equação de Murray (1967):

$$
t_{o}\left({ }^{\circ} C\right)=\frac{237,3 \cdot \log \left(e_{a} / 6,10\right)}{7,5-\log \left(e_{a} / 6,10\right)}
$$

\subsection{Procedimentos estatísticos}

De posse dos dados da $\mathrm{ET}_{0}$, pelos diferentes métodos citados, foram calculadas as estatísticas descritivas. Em seguida comparou-se, as médias dos diferentes métodos, com a $\mathrm{ET}_{0}$ pelo método padrão de Penman-Moteith $\left(E T_{0} P M\right.$ ) por meio do teste $\mathrm{t}$ de Student com nível de confiança estatística de 95\%, para averiguar se são significativamente diferentes.

Em seguida, fez-se uma avaliação, sazonal e anual dos métodos, adotando-se como referência a $E T_{0} P M$. O método da correlação de Pearson foi utilizado para encontrar a relação existente entre os métodos, em análise, com a $E T_{0} P M$, sendo $X$ a $E_{0} \mathrm{PM}$ e $Y$, individualmente, cada um dos métodos de $E T_{0}$ em análise ( $\mathrm{ET}_{0} \mathrm{RS}, \mathrm{ET}_{0} \mathrm{HS}, \mathrm{ET}_{0} \mathrm{~L}$ e $\left.\mathrm{ET}_{0} \mathrm{TCA}\right)$ e "n" é o número de observações de acordo com a equação 6. 


$$
r=\frac{n \sum_{i=1}^{n} X_{i} Y_{i}-\left(\sum_{i=1}^{n} X_{i}\right)\left(\sum_{i=1}^{n} Y_{i}\right)}{\sqrt{n \sum_{i=1}^{n} X_{i}^{2}-\left(\sum_{i=1}^{n} X_{i}\right)^{2}} \sqrt{n \sum_{i=1}^{n} Y_{i}^{2}-\left(\sum_{i=1}^{n} Y_{i}\right)^{2}}}
$$

O coeficiente de correlação (r) pode variar de -1 a 1, ou seja, correlação negativa ou positiva, perfeitas, $\mathrm{r}$ mais próximo do valor zero indica fraca ou ausência da correlação. Para identificar a proporção da variação entre a $E T_{0} P M$ com outros métodos de $E T_{0}$ analisados neste trabalho, calculou-se o coeficiente de Determinação $\left(\mathrm{R}^{2}\right)$, dado por:

$$
R^{2}=\frac{S Q_{r e g}}{S Q_{t o t}}
$$

Sendo R²: Coeficiente de Determinação;

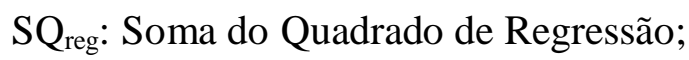

SQ tot: Soma do Quadrado Total.

Em seguida, o modelo de regressão simples (equação 8) foi determinado para os métodos de estimativas da $E T_{0}$ que atenderam aos pressupostos (linearidade, normalidade, independência e homocedasticidade). Sendo considerada a variável independente $(X)$ em relação ao observado - $E T_{0} P M(Y)$. Os coeficientes linear (a) e angular (b) são os parâmetros que indicam por meio do teste de significância, a interdependência.

$$
Y=a+b X
$$

Para complementar e validar os resultados foram calculados os índices de concordância ou exatidão (“d”) (equação 9) que se referem ao distanciamento médio entre os valores observados e o de referência. O Erro Médio Absoluto (EMA) (equação 10), o Desvio Médio Relativo (DMR) (equação 11), e o índice de desempenho (“c”) (equação 12), também foram calculados obtendo-se sempre como referência o método padrão - $E T_{0} P M-$ de acordo com equações propostas por Willmott et al. (1985). 


$$
\begin{gathered}
d=1-\frac{\sum_{1}^{n}\left(E_{i}-O_{i}\right)^{2}}{\sum_{1}^{n}\left(\left|E_{i}-O\right|+\left|O_{i}-O\right|\right)^{2}} \\
E M A=\frac{1}{n} \sum_{1}^{n}\left|O_{i}-E_{i}\right| \\
D M R=\sqrt{\frac{\sum \frac{\left(E_{i}-O_{i}\right)^{2}}{O_{i}}}{N}} \times(100) \\
c=|r \times d|
\end{gathered}
$$

Em que: $O_{i}-\mathrm{ET}_{0}$ estimada pelo método da FAO-56 Penman-Montheit;

$O-\mathrm{ET}_{0}$ estimada pelo método da FAO-56 Penman-Montheit;

$E_{i}-\mathrm{ET}_{0}$ estimada pelo método em avaliação;

$N$ - número de estimativas.

De acordo com o valor de "c" o desempenho das estimativas foi categorizado de acordo com critérios estabelecidos por Camargo e Sentelhas (1997), Tabela 1.

Tabela 1. Valores dos coeficientes de Desempenho proposto por Camargo e Sentelhas (1997).

\begin{tabular}{cc}
\hline \hline Valor de "c" & Desempenho \\
\hline \hline$>0,85$ & Ótimo \\
0,76 a 0,85 & Muito bom \\
0,66 a 0,75 & Bom \\
0,61 a 0,65 & Mediano \\
0,51 a 0,60 & Sofrível \\
0,41 a 0,50 & Mau \\
$\leq 0,40$ & Péssimo \\
\hline
\end{tabular}

Para realização dos cálculos, testes estatísticos e elaboração de gráficos utilizou-se o software estatístico livre "R", versão 3.3.1 


\section{RESULTADOS E DISCUSSÃO}

Observam-se nas Figuras 2 e 3, respectivamente para Juazeiro e Petrolina, o comportamento médio diário da $\mathrm{ET}_{0} \mathrm{PM}$ e por outros cinco métodos $\left(\mathrm{ET}_{0} \mathrm{RS}, \mathrm{ET}_{0} \mathrm{HS}, \mathrm{ET}_{0} \mathrm{~L}\right.$ e $\left.\mathrm{ET}_{0} \mathrm{TCA}\right)$. Nota-se que há uma concordância, entre os métodos para os meses em que ocorrem os picos de maior valor (outubro) e o de menor (junho). Entretanto a $\mathrm{ET}_{0} \mathrm{PM}$ é superestimada pelos métodos analisados com predominância nos doze meses do ano, exceto para o método de estimativa da $\mathrm{ET}_{0}$ pelo Tanque Classe "A" utilizando o coeficiente de conversão (Kp) proposto por Pereira (ET, $\left.\mathrm{ECA}_{0} \mathrm{P}\right)$.

Constata-se que a conversão de evaporação, em $\mathrm{ET}_{0}$, utilizando-se o método do Tanque Classe $\mathrm{A}$ ( $\left.\mathrm{ET}_{0} \mathrm{TCA}\right)$, foi o mais irregular (em relação à $\mathrm{ET}_{0} \mathrm{PM}$ ), tanto para o coeficiente de conversão proposto por Snyder (1992) (superestimativa cerca de 31,28\%) quanto para o de Pereira et al. (1995) (subestimativa cerca de 15,1\%), em ambas as localidades. Entre os métodos que mais se assemelharam estão: Radiação Solar $\left(\mathrm{ET}_{0} \mathrm{RS}\right)$ e Linacre $\left(\mathrm{ET}_{0} \mathrm{~L}\right)$, com uma diferença de $12 \%$, em média (Figuras 2 e 3 ).

\section{Juazeiro, BA}

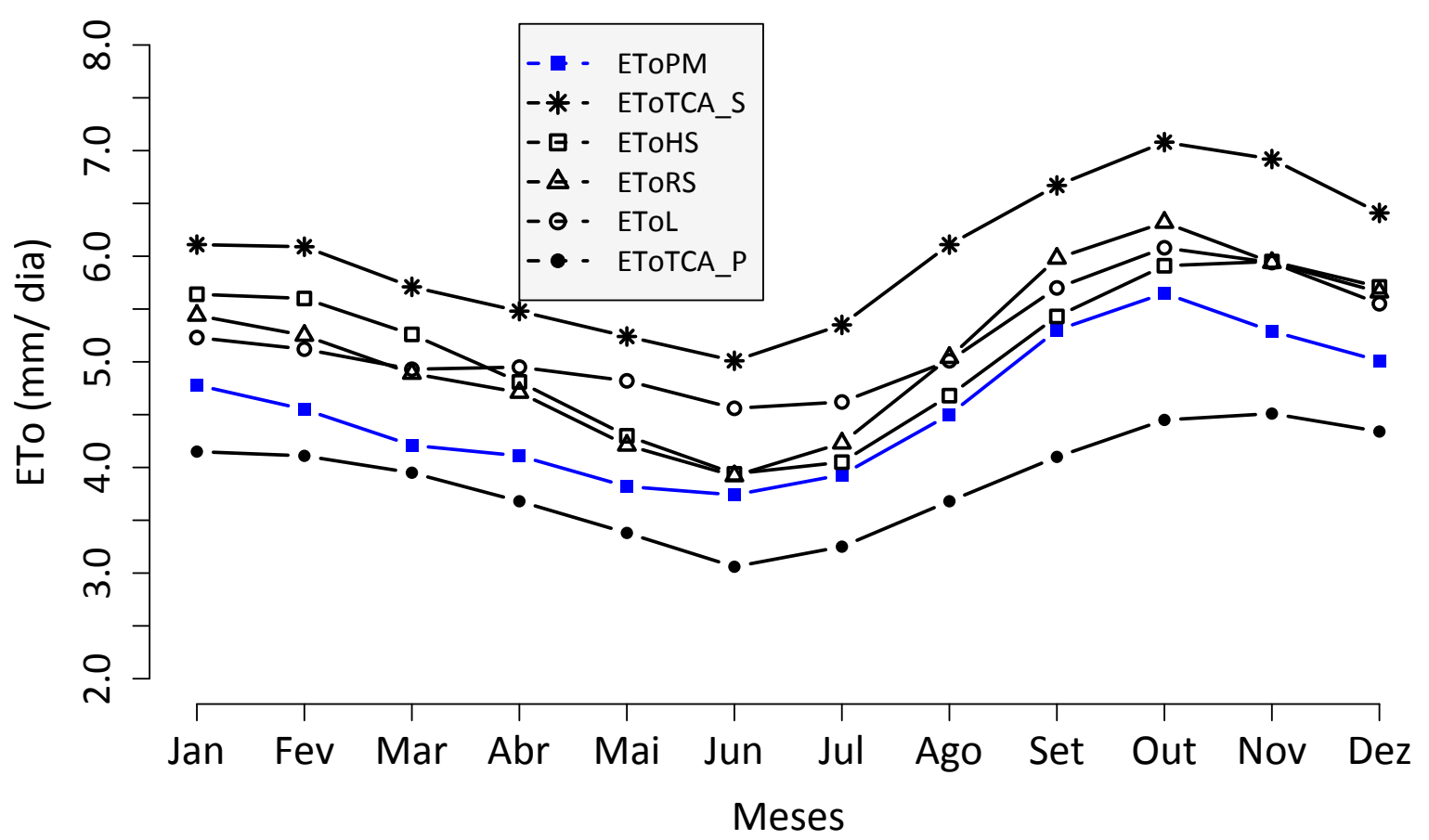

Figura 2. Médias diárias mensais da evapotranspiração de referência $\left(\mathrm{ET}_{0}\right)$, estimadas pelos métodos de Penman-Monteith, Hargreaves e Samani (ET $\left.\mathrm{ET}_{0} \mathrm{HS}\right)$, Radiação Solar $\left(\mathrm{ET}_{0} \mathrm{RS}\right)$, Linacre $\left(\mathrm{ET}_{0} \mathrm{~L}\right)$ e o método do Tanque Classe A, utilizando-se coeficientes de conversão de evaporação em ET $_{0}$ proposto por: Snyder

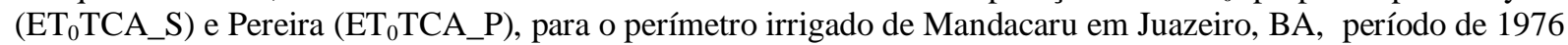
a 2014. Fonte: Elaborado pelo primeiro autor. 


\section{Petrolina, PE}

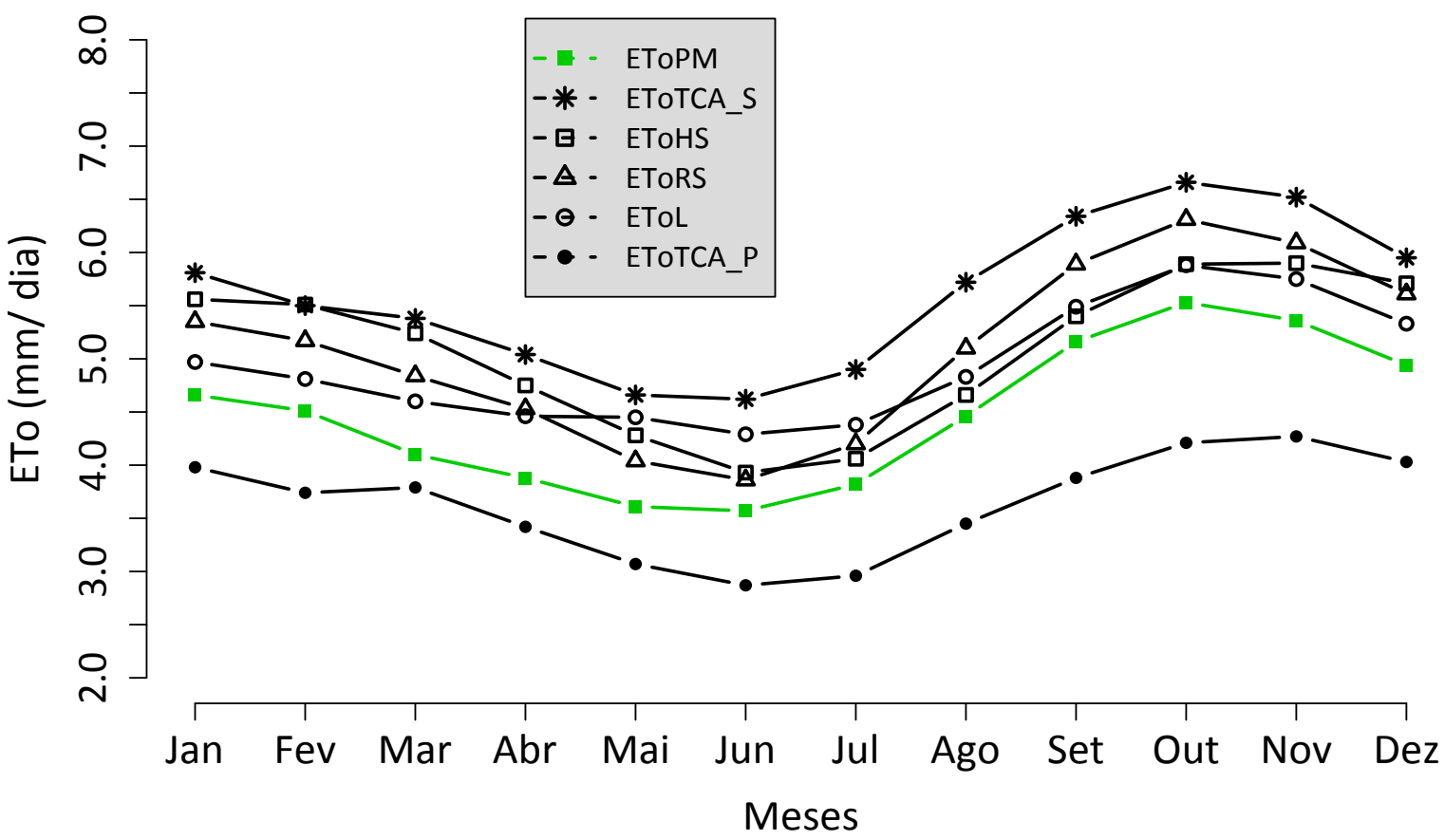

Figura 3. Médias diárias mensais da evapotranspiração de referência $\left(\mathrm{ET}_{0}\right)$, estimadas pelos métodos de Penman-Monteith, Hargreaves e Samani (ET $\left.\mathrm{ET}_{0} \mathrm{HS}\right)$, Radiação Solar $\left(\mathrm{ET}_{0} \mathrm{RS}\right)$, Linacre $\left(\mathrm{ET}_{0} \mathrm{~L}\right)$ e o método do Tanque Classe A, utilizando-se coeficientes de conversão de evaporação em ET $_{0}$ proposto por: Snyder (ET $\mathrm{ET}_{0} \mathrm{TC} \_\mathrm{S}$ ) e Pereira (ET $\mathrm{TCA}$ _P) para o perímetro irrigado de Bebedouro em Petrolina, PE, período de 1976 a 2014. Fonte: Elaborado pelo primeiro autor.

Para avaliar a relação sazonal entre a $\mathrm{ET}_{0} \mathrm{PM}$ com estimativas mais simplificadas da $\mathrm{ET}_{0}$, fez-se: as correlações (r) e as respectivas significâncias estatísticas, o coeficiente de determinação $\left(\mathrm{R}^{2}\right)$, o teste de média (teste " $\mathrm{t}$ " - pareado) e as diferenças das médias através do teste de Tukey (em mm/dia) com as respectivas significâncias, observadas na Tabela 2. Verificou-se que a melhor correlação foi para o método da $\mathrm{ET}_{0} \mathrm{RS}$, com correlações iguais ou superiores a 0,93 e com significância estatística de 1\%, para ambas as localidades. Os piores métodos oscilaram entre o método do Tanque Classe A e o de Hargreaves e Samani.

Os resultados encontrados, através do teste "t" e pelo Teste de Tukey permitiram identificar que a $\mathrm{ET}_{0} \mathrm{RS}$ e $\mathrm{ET}_{0} \mathrm{~L}$ obtiveram as melhores correlações com a $\mathrm{ET}_{0} \mathrm{PM}$ (" $r$ " $\geq 0,93$ ) porém os valores comparados entre si apresentaram magnitudes diferentes, ou seja, as médias diferem com uma confiança estatística de 99\%. Esses resultados concordam com as afirmações de Allen et al. (1998) e Pereira et al. (2014) ao mencionarem que os valores de $\mathrm{ET}_{0}$ e as diferenças quando se compara a outros métodos de análise, fica condicionado ao local, às condições climáticas e à época do ano.

Analisando sazonalmente, o outono foi a estação do ano em que obteve a maior correlação $(0,98)$ para as duas localidades, entre a $\mathrm{ET}_{0} \mathrm{PM}$ e a $\mathrm{ET}_{0} \mathrm{RS}$, e com significância 
estatística (valor-p $<0,01$ ), porém refutou-se a hipótese de igualdade de médias por meio do teste "t" (p-valor < 0,01). Comprovando-se que há forte correlação, porém os valores médios diferem entre si, com uma diferença de $0,56 \mathrm{~mm} \cdot \mathrm{dia}^{-1}$ (Juazeiro) e 0,61 mm.dia ${ }^{-1}$ (Petrolina), confirmado pelo teste de Tukey a $1 \%$ de significância estatística.

A correlação entre os valores de $\mathrm{ET}_{0} \mathrm{PM}$ e os estimados pelos demais métodos, para as duas localidades, indica que o método da $\mathrm{ET}_{0} \mathrm{HS}$ seja o pior, cujas correlações nas quatro estações do ano não foram significativas. Destacando-se que mesmo tendo ocorrido uma exceção (para o período do inverno em Juazeiro) de este método obter médias semelhantes (teste “t”), porém os coeficientes de correlação $(r=0,18)$ não foram significativos.

Tabela 2. Coeficiente de correlação (r) e determinação $\left(\mathrm{R}^{2}\right)$, teste de média (teste " $t$ ") e teste com a diferença média (teste de Tukey), entre a $\mathrm{ET}_{0} \mathrm{PM}$ (Penman-Monteith-FAO) comparada aos métodos da $\mathrm{ET}_{0} \mathrm{RS}, \mathrm{ET}_{0} \mathrm{HS}_{\text {, }}$ $\mathrm{ET}_{0} \mathrm{~L}, \mathrm{ET}_{0} \mathrm{TCA} \_\mathrm{S}$ e ET 0 TCA_P, por estação do ano, nos perímetros irrigados de Mandacaru em Juazeiro, BA e de Bebedouro em Petrolina, PE, no período de 1976 a 2014. Fonte: Elaborado pelo primeiro autor.

\begin{tabular}{|c|c|c|c|c|c|c|c|c|}
\hline \multirow{3}{*}{$\underline{\text { Métodos }}$} & \multicolumn{8}{|c|}{ Verão } \\
\hline & \multicolumn{4}{|c|}{ Juazeiro, BA. } & \multicolumn{4}{|c|}{ Petrolina, PE. } \\
\hline & $\mathrm{r}$ & $\mathrm{R}^{2}$ & $\begin{array}{l}\text { Teste " } t \text { " } \\
\text { (valor-p) }\end{array}$ & $\begin{array}{c}\text { Tukey } \\
\text { (mm/dia) }\end{array}$ & $\mathrm{r}$ & $\mathrm{R}^{2}$ & $\begin{array}{l}\text { Teste "t" } \\
\text { (valor-p) }\end{array}$ & $\begin{array}{c}\text { Tukey } \\
\text { (mm/dia) }\end{array}$ \\
\hline $\mathrm{ET}_{0} \mathrm{RS}$ & $0,96 * * *$ & 0,93 & $<0,01$ & $0,68 * * *$ & $0,95 * * *$ & 0,91 & $<0,01$ & $0,68 * * *$ \\
\hline $\mathrm{ET}_{0} \mathrm{HS}$ & 0,21 & 0,04 & $<0,01$ & $0,87 * * *$ & 0,26 & 0,07 & $<0,01$ & $0,86^{* * *}$ \\
\hline $\mathrm{ET}_{0} \mathrm{~L}$ & $0,81 * * *$ & 0,66 & $<0,01$ & $0,50 * * *$ & $0,82 * * *$ & 0,67 & $<0,01$ & $0,33 * * *$ \\
\hline $\mathrm{ET}_{0} \mathrm{TCA} \_\mathrm{S}$ & $0,50 * * *$ & 0,25 & $<0,01$ & $1,41 * * *$ & $0,43 * * *$ & 0,18 & $<0,01$ & $1,03 * * *$ \\
\hline \multirow[t]{3}{*}{$\mathrm{ET}_{0} \mathrm{TCA} \mathrm{P}$} & $0,52 * * *$ & 0,27 & $<0,01$ & $-0,59 * * *$ & $0,32 * *$ & 0,10 & $<0,01$ & $0,81 * * *$ \\
\hline & \multicolumn{8}{|c|}{ Outono } \\
\hline & \multicolumn{4}{|c|}{ Juazeiro, BA. } & \multicolumn{4}{|c|}{ Petrolina, PE. } \\
\hline$\underline{\text { Métodos }}$ & $\mathrm{r}$ & $\mathrm{R}^{2}$ & $\begin{array}{l}\text { Teste " } \mathrm{t} \text { " } \\
\text { (valor-p) }\end{array}$ & $\begin{array}{c}\text { Tukey } \\
\text { (mm/dia) }\end{array}$ & $\mathrm{r}$ & $\mathrm{R}^{2}$ & $\begin{array}{l}\text { Teste " } t \text { " } \\
\text { (valor-p) }\end{array}$ & $\begin{array}{c}\text { Tukey } \\
\text { (mm/dia) }\end{array}$ \\
\hline $\mathrm{ET}_{0} \mathrm{RS}$ & $0,98 * * *$ & 0,96 & $<0,01$ & $0,56 * * *$ & $0,98 * * *$ & 0,97 & $<0,01$ & $0,61 * * *$ \\
\hline $\mathrm{ET}_{0} \mathrm{HS}$ & 0,20 & 0,04 & $<0,01$ & $0,75^{* * *}$ & 0,26 & 0,07 & $<0,01$ & $0,87 * * *$ \\
\hline $\mathrm{ET}_{0} \mathrm{~L}$ & $0,81 * * *$ & 0,66 & $<0,01$ & $0,84 * * *$ & $0,84 * * *$ & 0,71 & $<0,01$ & $0,64 * * *$ \\
\hline $\mathrm{ET}_{0} \mathrm{TCA} \_\mathrm{S}$ & $0,52 * * *$ & 0,27 & $<0,01$ & $1,42 * * *$ & $0,51 * * *$ & 0,27 & $<0,01$ & $1,15^{* * *}$ \\
\hline \multirow[t]{3}{*}{$\mathrm{ET}_{0} \mathrm{TCA} \_\mathrm{P}$} & $0,56 * * *$ & 0,29 & $<0,01$ & $0,38 * * *$ & $0,39 * *$ & 0,16 & $<0,01$ & $0,45 * * *$ \\
\hline & \multicolumn{8}{|c|}{ Inverno } \\
\hline & \multicolumn{4}{|c|}{ Juazeiro, BA. } & \multicolumn{4}{|c|}{ Petrolina, PE. } \\
\hline Metodos & $\mathrm{r}$ & $\mathrm{R}^{2}$ & $\begin{array}{l}\text { Teste " } t \text { " } \\
\text { (valor-p) }\end{array}$ & $\begin{array}{c}\text { Tukey } \\
\text { (mm/dia) }\end{array}$ & $\mathrm{r}$ & $\mathrm{R}^{2}$ & $\begin{array}{l}\text { Teste " } t \text { " } \\
\text { (valor-p) }\end{array}$ & $\begin{array}{c}\text { Tukey } \\
\text { (mm/dia) }\end{array}$ \\
\hline $\mathrm{ET}_{0} \mathrm{RS}$ & $0,94 * * *$ & 0,88 & $<0,01$ & $0,35 * * *$ & $0,95 * * *$ & 0,90 & $<0,01$ & $0,43 * * *$ \\
\hline $\mathrm{ET}_{0} \mathrm{HS}$ & 0,18 & 0,03 & 0,11 & 0,18 & 0,07 & 0,00 & $<0,05$ & $0,24 * *$ \\
\hline $\mathrm{ET}_{0} \mathrm{~L}$ & $0,89 * * *$ & 0,80 & $<0,01$ & $0,67 * * *$ & $0,82 * * *$ & 0,67 & $<0,01$ & $0,54 * * *$ \\
\hline $\mathrm{ET}_{0} \mathrm{TCA} \_\mathrm{S}$ & $0,57 * * *$ & 0,32 & $<0,01$ & $1,43 * * *$ & 0,25 & 0,06 & $<0,01$ & $1,10 * * *$ \\
\hline
\end{tabular}




\begin{tabular}{|c|c|c|c|c|c|c|c|c|}
\hline $\mathrm{ET}_{0} \mathrm{TCA} \_\mathrm{P}$ & $0,58 * * *$ & 0,34 & $<0,01$ & $0,73 * * *$ & $0,39 * *$ & 0,15 & $<0,01$ & $0,89 * * *$ \\
\hline & \multicolumn{8}{|c|}{ Primavera } \\
\hline \multirow{2}{*}{$\underline{\text { Métodos }}$} & \multicolumn{4}{|c|}{ Juazeiro, BA. } & \multicolumn{4}{|c|}{ Petrolina, PE. } \\
\hline & $\mathrm{r}$ & $\mathrm{R}^{2}$ & $\begin{array}{l}\text { Teste " } \mathrm{t} \text { " } \\
\text { (valor-p) }\end{array}$ & $\begin{array}{c}\text { Tukey } \\
\text { (mm/dia) }\end{array}$ & $\mathrm{r}$ & $\mathrm{R}^{2}$ & $\begin{array}{l}\text { Teste "t" } \\
\text { (valor-p) }\end{array}$ & $\begin{array}{c}\text { Tukey } \\
\text { (mm/dia) }\end{array}$ \\
\hline $\mathrm{ET}_{0} \mathrm{RS}$ & $0,93 * * *$ & 0,87 & $<0,01$ & $0,67 * * *$ & $0,96 * * *$ & 0,92 & $<0,01$ & $0,65 * * *$ \\
\hline $\mathrm{ET}_{0} \mathrm{HS}$ & 0,38 & 0,15 & $<0,05$ & $0,35^{* *}$ & 0,11 & 0,01 & $<0,05$ & $0,36 * *$ \\
\hline $\mathrm{ET}_{0} \mathrm{~L}$ & $0,81 * * *$ & 0,65 & $<0,01$ & $0,48 * * *$ & $0,73 * * *$ & 0,53 & $<0,01$ & $0,35 * *$ \\
\hline $\mathrm{ET}_{0} \mathrm{TCA} \_\mathrm{S}$ & 0,20 & 0,04 & $<0,01$ & $1,46 * * *$ & 0,08 & 0,01 & $<0,01$ & $1,15^{* * *}$ \\
\hline $\mathrm{ET}_{0} \mathrm{TCA}$ _P & 0,18 & 0,03 & $<0,01$ & $1,07 * * *$ & 0,16 & 0,02 & $<0,01$ & $1,24 * * *$ \\
\hline
\end{tabular}

**5\% de significância; $* * * 1 \%$ de significância.

Nas Figuras 4 e 5 são apresentadas, através de gráficos de caixa (boxplots) a dispersão dos dados médios diários, por ano, da $\mathrm{ET}_{0}$, pelo método padrão (referencial). Em ordem crescente os valores médios da $\mathrm{ET}_{0}$ pelos métodos mais simplificados em análise, para Juazeiro, foram: $\mathrm{ET}_{0} \mathrm{TCA}_{-} \mathrm{P}, \mathrm{ET}_{0} \mathrm{HS}, \mathrm{ET}_{0} \mathrm{RS}, \mathrm{ET}_{0} \mathrm{~L}$ e ET 0 TCA_S, enquanto que a ordem crescente para os métodos simplificados em Petrolina foram: $\mathrm{ET}_{0} \mathrm{TCA}_{\mathrm{P}} \mathrm{P}, \mathrm{ET}_{0} \mathrm{~L}, \mathrm{ET}_{0} \mathrm{HS}$, $\mathrm{ET}_{0} \mathrm{RS}$ e ET 0 TCA_S.

Verificou-se pelo teste " $\mathrm{t}$ " (pareado), assim como foi observado por estação do ano, que as médias diárias anuais da $\mathrm{ET}_{0} \mathrm{PM}$ comparada com cada método em análise, foram diferentes com significância estatística de 5\%. Para Juazeiro foi confirmado que a diferença média, da $\mathrm{ET}_{0} \mathrm{PM}$ com os outros métodos foram: -0,7 mm (ET $\left.\mathrm{ETCA}_{0} \mathrm{P}\right), 0,5 \mathrm{~mm}$ ( $\left.\mathrm{ET}_{0} \mathrm{HS}\right), 0,6$ mm (ET $\left.\mathrm{ETS}_{0}\right), 0,6 \mathrm{~mm}\left(\mathrm{ET}_{0} \mathrm{~L}\right)$ e 1,43 mm (ET $\left.\mathrm{ECA}_{0} \mathrm{~S}\right)$. Enquanto que para Petrolina, as diferenças foram: -0,9 mm (ET $\left.\mathrm{ETCA}_{0} \mathrm{P}\right), 0,5 \mathrm{~mm}\left(\mathrm{ET}_{0} \mathrm{~L}\right)$ 0,6 mm $\left(\mathrm{ET}_{0} \mathrm{HS}\right), 0,6 \mathrm{~mm}\left(\mathrm{ET}_{0} \mathrm{RS}\right)$,

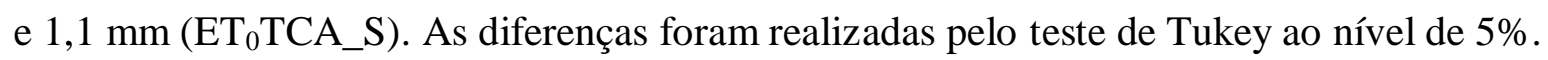

Ao comparar o valor da $\mathrm{ET}_{0} \mathrm{PM}$ de Juazeiro com Petrolina, identificou-se através do teste "t" (não pareado) que a hipótese de igualdade entre as médias não foi refutada com 95\% de confiança estatística e que o valor da diferença foi de $0,1 \mathrm{~mm}$ (a mais para Juazeiro). 


\section{Juazeiro, BA.}

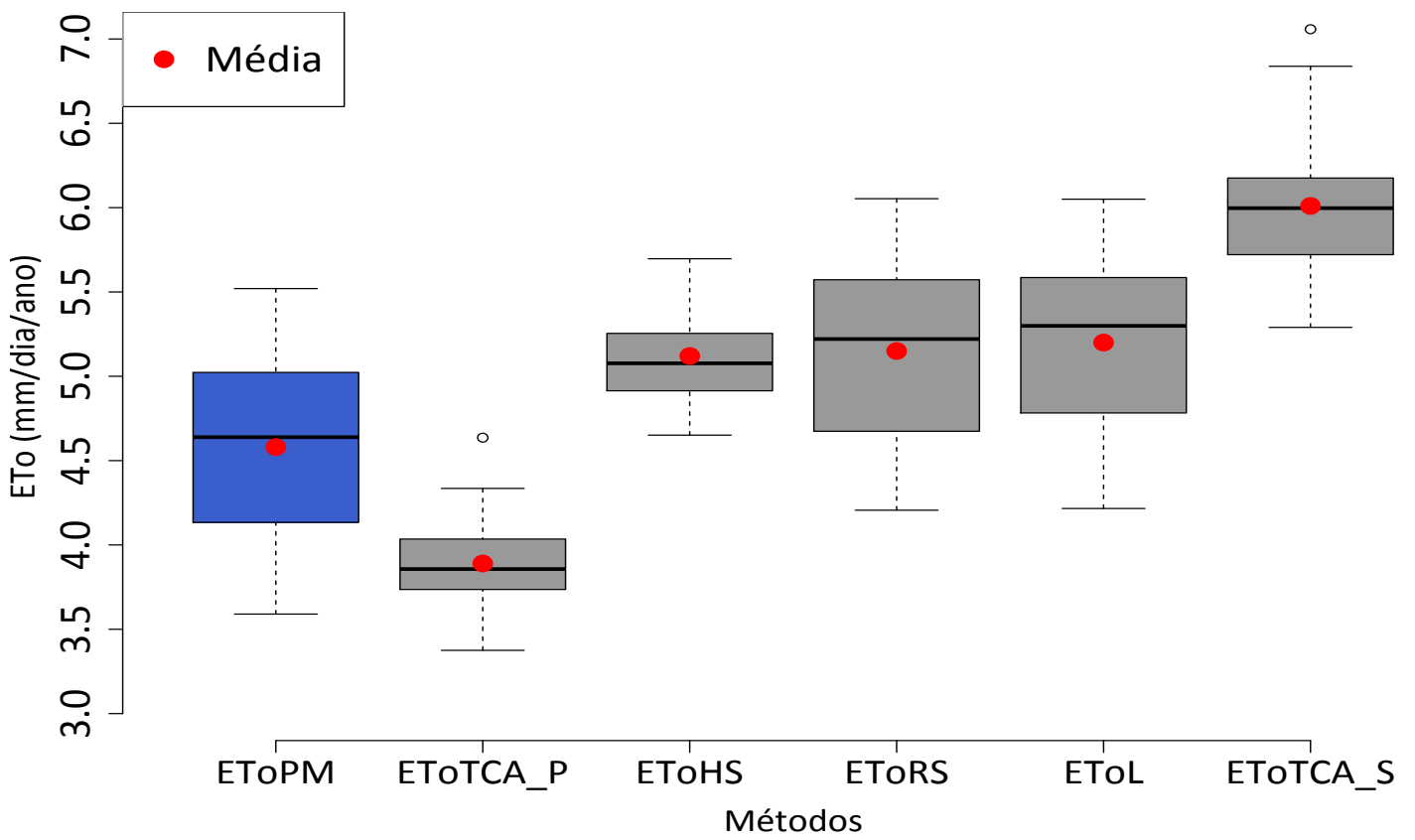

Figura 4. Box Plot com distribuição média diária por ano, obtida pelos métodos de Penman-Monteith (ET $\left.\mathrm{E}_{0} \mathrm{PM}\right)$, Hargreaves e Samani (ET $\left.\mathrm{ET}_{0} \mathrm{HS}\right)$, Radiação Solar $\left(\mathrm{ET}_{0} \mathrm{RS}\right)$, Linacre $\left(\mathrm{ET}_{0} \mathrm{~L}\right)$ e o método do Tanque Classe A, utilizando-se coeficientes de conversão de evaporação em ET $_{0}$ proposto por Snyder (ET ${ }_{0}$ TCA_S) e Pereira (ET $\left.\mathrm{TCA}_{0} \mathrm{P}\right)$, e os respectivos intervalos da média \pm Desvio Padrão (DP) da $\mathrm{ET}_{0} \mathrm{PM}$ para o perímetro irrigado de Mandacaru em Juazeiro, BA, no período de 1976 a 2014. Fonte: Elaborado pelo primeiro autor.

\section{Petrolina, PE.}

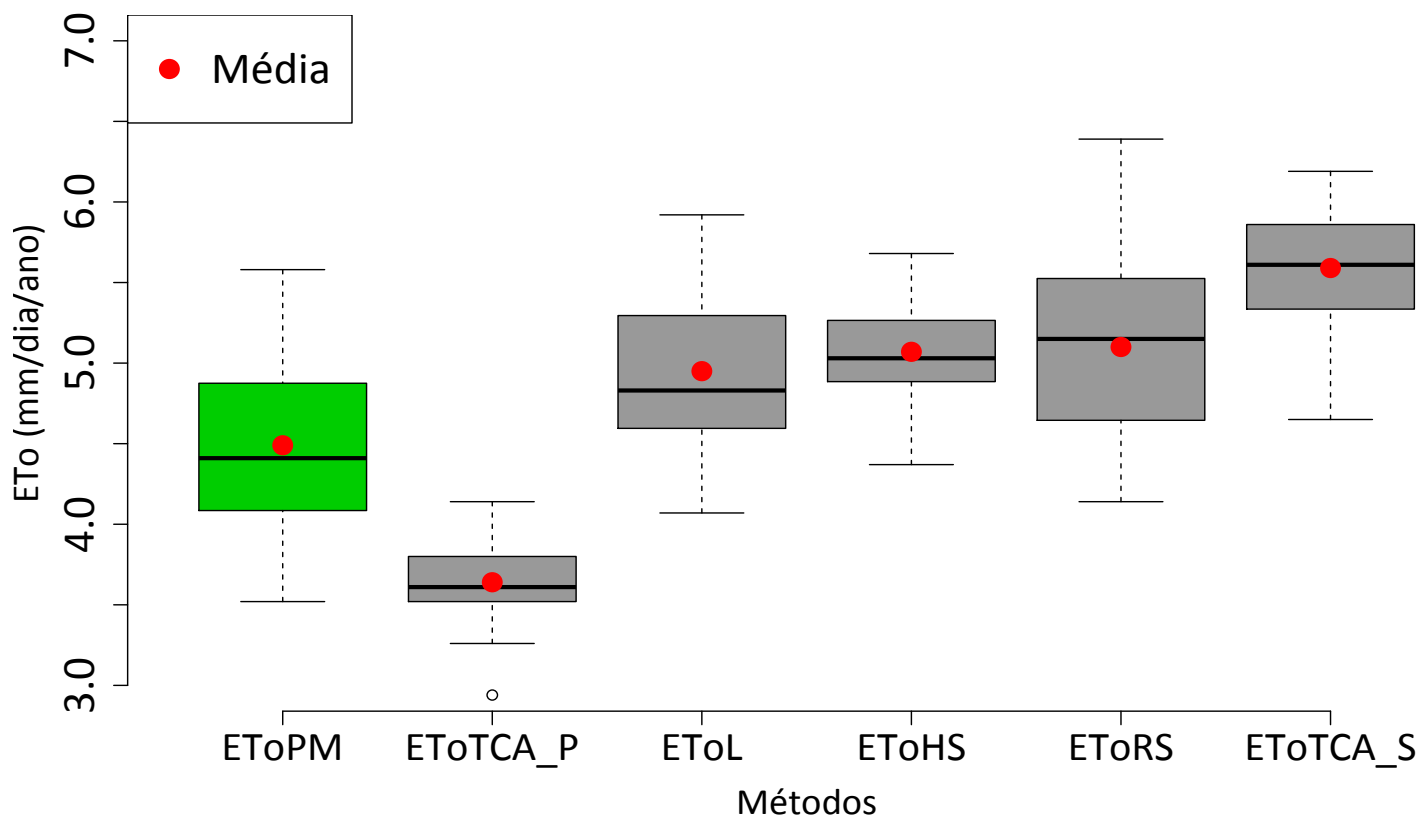

Figura 5. Box Plot com distribuição média diária por ano, obtida pelos métodos de Penman-Monteith $\left(\mathrm{ET}_{0} \mathrm{PM}\right)$, Hargreaves e Samani (ET $\left.\mathrm{ET}_{0} \mathrm{HS}\right)$, Radiação Solar $\left(\mathrm{ET}_{0} \mathrm{RS}\right)$, Linacre $\left(\mathrm{ET}_{0} \mathrm{~L}\right)$ e o método do Tanque Classe A, utilizando-se coeficientes de conversão de evaporação em ET $_{0}$ proposto por Snyder (ET 0 TCA_S) e Pereira

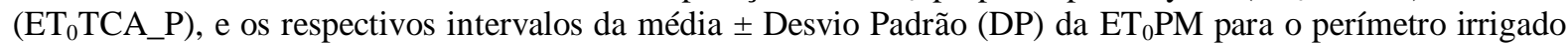
de Bebedouro, Petrolina, PE, no período de 1976 a 2014. Fonte: Elaborado pelo primeiro autor. 
As estatísticas propostas por Willmott et al. (1985) foram analisadas (índice de exatidão ou concordância - "D" e o Erro Médio Absoluto - EMA), assim como o coeficiente de determinação $\left(\mathrm{R}^{2}\right)$, a correlação (r), o índice de desempenho dos métodos em questão ("c") e o modelo de regressão linear, todos esses identificados na Tabela 3, sendo apresentados em ordem decrescente de acordo com os índices de desempenho ("c") dos métodos de estimava em questão relacionados à $\mathrm{ET}_{0} \mathrm{PM}$.

Tabela 3. Avaliação do desempenho dos métodos para a estimativa da Evapotranspiração de referência $\left(E_{0}\right)$ diária, estimada pelos métodos: $\mathrm{ET}_{0} \mathrm{RS}, \mathrm{ET}_{0} \mathrm{HS}, \mathrm{ET}_{0} \mathrm{~L}$ e pelo método do Tanque Classe $\mathrm{A}$ com diferentes

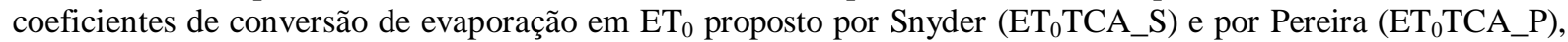
comparados ao método padrão (ET $\left.\mathrm{ET}_{0} \mathrm{PMAO}\right)$ em perímetros irrigados de Juazeiro, BA e Petrolina, PE, no período de 1976 a 2014. Fonte: Elaborado pelo primeiro autor.

Juazeiro, BA.

\begin{tabular}{cccccccc}
\hline Métodos & D & EMA & $\mathbf{R}^{2}$ & $\mathbf{R}$ & $\mathbf{c}$ & Desempenho & Regressão Linear \\
$\mathrm{ET}_{0} \mathrm{RS}$ & 0,79 & 0,57 & 0,93 & 0,96 & 0,76 & Muito Bom & $\mathrm{ET}_{0} \mathrm{PM}=-0,400+0,968 * \mathrm{ET}_{0} \mathrm{RS}$ \\
$\mathrm{ET}_{0} \mathrm{~L}$ & 0,77 & 0,62 & 0,72 & 0,85 & 0,66 & Bom & $\mathrm{ET}_{0} \mathrm{PM}=-0,003+0,881 * \mathrm{ET}_{0} \mathrm{~L}$ \\
$\mathrm{ET}_{0} \mathrm{TCA} \_\mathrm{P}$ & 0,52 & 0,72 & 0,17 & 0,41 & 0,21 & Péssimo & - \\
$\mathrm{ET}_{0} \mathrm{TCA} \_\mathrm{S}$ & 0,38 & 1,43 & 0,12 & 0,35 & 0,13 & Péssimo & - \\
$\mathrm{ET}_{0} \mathrm{HS}$ & 0,38 & 0,66 & 0,07 & 0,27 & 0,10 & Péssimo & - \\
\hline
\end{tabular}

Petrolina, PE.

\begin{tabular}{cccccccc} 
Métodos & $\mathbf{D}$ & EMA & $\mathbf{R}^{2}$ & $\mathbf{R}$ & $\mathbf{c}$ & Desempenho & Regressão Linear \\
$\mathrm{ET}_{0} \mathrm{RS}$ & 0,79 & 0,62 & 0,96 & 0,98 & 0,77 & Muito Bom & $\mathrm{ET}_{0} \mathrm{PM}=-0,124+0,903 * \mathrm{ET}_{0} \mathrm{RS}$ \\
$\mathrm{ET}_{0} \mathrm{~L}$ & 0,76 & 0,47 & 0,65 & 0,81 & 0,62 & Mediano & $\mathrm{ET}_{0} \mathrm{PM}=-0,06+0,919 * \mathrm{ET}_{0} \mathrm{~L}$ \\
$\mathrm{ET}_{0} \mathrm{TCA}_{\mathrm{T}} \mathrm{P}$ & 0,44 & 0,87 & 0,05 & 0,41 & 0,18 & Péssimo & - \\
$\mathrm{ET}_{0} \mathrm{TCA} \mathrm{S}$ & 0,41 & 1,11 & 0,06 & 0,25 & 0,10 & Péssimo & - \\
$\mathrm{ET}_{0} \mathrm{HS}$ & 0,47 & 0,64 & 0,00 & 0,05 & 0,02 & Péssimo & - \\
\hline
\end{tabular}

Para Juazeiro, os métodos de estimativa da $\mathrm{ET}_{0}$ baseados na radiação solar e Linacre superestimaram a $\mathrm{ET}_{0}$ padrão $\left(\mathrm{ET}_{0} \mathrm{PM}\right) \mathrm{em}$ 12,40 e 11,7\%, com EMA de 0,57 e 0,62 mm.dia ${ }^{-1}$ e respectivamente obtiveram altos $\mathrm{R}^{2}(0,93$ e 0,72$)$, " $\mathrm{r}$ " (0,96 e 0,85). Esses métodos foram os que apresentaram o melhor desempenho em relação aos demais, destacando-se o método da $\mathrm{ET}_{0} \mathrm{RS}$ com maior valor de "c" $(0,76)$ seguido da $\mathrm{ET}_{0} \mathrm{~L}(0,66)$ cujas classificações dos desempenhos são: "Muito bom" e "Bom" (CAMARGO \& SENTELHAS, 1997). Os resíduos da $\mathrm{ET}_{0} \mathrm{PM}$ versus $\mathrm{ET}_{0} \mathrm{RS}$, e $\mathrm{ET}_{0} \mathrm{PM}$ versus $\mathrm{ET}_{0} \mathrm{~L}$ foram verificados de acordo com os testes estatísticos de: normalidade (Shapiro-Wilk), independência (Durbin-Watson) e homocedasticidade (Breusch-Pagan), sendo validados com significância estatística de 5\%. 
A regressão linear foi determinada (Tabela 3) para a $\mathrm{ET}_{0} \mathrm{RS}$ e para a $\mathrm{ET}_{0} \mathrm{~L}$. Os coeficientes angulares, para os dois métodos, foram significativos a 5\%. Para os demais métodos (ET 0 TCA_P, ET 0 TCA_S e ET 0 HS), em Juazeiro, obtiveram correlação fraca e/ou ausente, baixos índices de concordância e desempenho péssimo, por isso não foi estabelecido o modelo de regressão.

Para Petrolina, também foram destaques a $\mathrm{ET}_{0} \mathrm{RS}$ e $\mathrm{ET}_{0} \mathrm{~L}$, nesta ordem, e apresentaram superestimativas à $\mathrm{ET}_{0} \mathrm{PM}$ de 13,8 e 13\%, com EMA de 0,62 e 0,47 mm.dia ${ }^{-1}$; $\mathrm{R}^{2}$ de 0,96 e 0,65 ; " $\mathrm{r}$ " de 0,98 e 0,81 ; “c" de 0,77 (desempenho Muito Bom) e 0,62 (desempenho mediano). Para esses métodos $\left(\mathrm{ET}_{0} \mathrm{RS}\right.$ e $\left.\mathrm{ET}_{0} \mathrm{~L}\right)$ também foram verificados: normalidade, independência e homocedasticidade, em relação à $\mathrm{ET}_{0} \mathrm{PM}$, cujos pressupostos foram verificados com significância estatística de 5\%, com ressalva para os resíduos da $\mathrm{ET}_{0} \mathrm{PM} \times \mathrm{ET}_{0} \mathrm{RS}$ (Petrolina), que foram dependentes a 1\% de significância. A regressão linear foi estabelecida para a $\mathrm{ET}_{0} \mathrm{RS}$ e para a $\mathrm{ET}_{0} \mathrm{~L}$ (Tabela 3), cujos coeficientes angulares, foram significativos a $5 \%$.

Outros trabalhos têm comparando a $\mathrm{ET}_{0} \mathrm{PM}$ com outros métodos de estimativas mais simplificados, afim de averiguar a exequibilidade e eficiência de um método que exija menos variáveis. Nessa perspectiva Oliveira et al. (2008) encontraram para a bacia experimental do Riacho Gameleira, PE que a $\mathrm{ET}_{0}$ estimada pelo método da Radiação Solar foi o que mais se ajustou aos valores obtidos com o lisímetro. No município de Capim, na Paraíba, Mendonça e Dantas (2010) verificaram que, das correlações obtidas com o método de Penman-Monteith, se destacaram a do método de Radiação, cujos coeficientes de determinação foram superiores a 0,80, esses resultados corroboram com os resultados nesta pesquisa, ao apresentar a $\mathrm{ET}_{0} \mathrm{RS}$ como o método de melhor correlação.

Ressalta-se também que a $\mathrm{ET}_{0}$ foi analisada por Sousa et al. (2009) em perímetros irrigados para as condições do estado de Sergipe, esses autores encontraram resultados semelhantes aos encontrados neste trabalho, e afirmaram que métodos de estimativas que utilizam a radiação solar apresentaram as melhores correlações com a $\mathrm{ET}_{0} \mathrm{PM}$. Entretanto os resultados aqui apresentados, discordam parcialmente dos resultados encontrados por Moura et al. (2013), em Vitória de Santo Antão, PE. Esses autores concluíram que o melhor método é o da Radiação Solar, o que ratifica com os resultados deste trabalho, porém esses mesmos autores encontraram forte correlação da $\mathrm{ET}_{0} \mathrm{PM}$ com a $\mathrm{ET}_{0} \mathrm{HS}$, o que não corroboram com os resultados demonstrados nesta pesquisa.

Resultados encontrados por Tagliaferre et al. (2010), ao analisarem a $\mathrm{ET}_{0}$ em Eunápolis, BA evidenciaram que a $\mathrm{ET}_{0} \mathrm{HS}$ se caracterizou como o pior método, enquanto que 
o método da Radiação apresentou-se como o melhor, considerando-se estatísticas descritivas e coeficientes de correlação. Em outro trabalho, Tagliaferre et al. (2011) estimaram a ET e $_{0}$ fizeram análise semelhante, em Guanambi, BA, e concluíram que, o método da Radiação Solar está entre os dois melhores para estimar a $\mathrm{ET}_{0}$. Silva et al. (2014) concordam ao relatar para o município de Petrolina, que o melhor método é o da $\mathrm{ET}_{0} \mathrm{RS}$.

\section{CONCLUSÕES}

De acordo com os resultados encontrados neste trabalho, conclui-se que a $\mathrm{ET}_{0} \mathrm{PM}$ é superestimada com predominância nas escalas mensal e anual quando se comparou a outros métodos de estimativas, exceto para o método de estimativa pelo Tanque Classe "A" utilizando o coeficiente de conversão $(\mathrm{Kp})$ proposto por Pereira (ET TCA_P ).

Foi observado uma alta correlação para o método da $\mathrm{ET}_{0} \mathrm{RS}$ comparada à $\mathrm{ET}_{0} \mathrm{PM}$, com correlações iguais ou superiores a 0,93 e com significância estatística de 1\%, as localidades analisadas. Os piores métodos oscilaram entre o método do $\mathrm{ET}_{0} \mathrm{TCA} \_\mathrm{P}$ e o de $\mathrm{ET}_{0} \mathrm{HS}$.

Sazonalmente o outono foi a estação do ano que se destacou com a maior correlação $(0,98)$, entre a $\mathrm{ET}_{0} \mathrm{PM}$ e a $\mathrm{ET}_{0} \mathrm{RS}$ significativos a $1 \%$, porém os valores comparados entre si apresentaram magnitudes diferentes, ou seja, as médias diferiram com uma confiança estatística de $99 \%$.

Sugere-se que em Juazeiro, BA e Petrolina, PE ao ser encontrada limitações de estimativa da $\mathrm{ET}_{0} \mathrm{PM}$, ausência de dados meteorológicos necessárias para o cálculo, pode-se utilizar métodos mais simplificados como o da Radiação Solar $\left(\mathrm{ET}_{0} \mathrm{RS}\right)$ e/ou o de Linacre $\left(\mathrm{ET}_{0} \mathrm{~L}\right)$ (ajustando-se à reta de regressão linear), cujos os métodos foram respectivamente os que obtiveram melhores desempenhos.

\section{REFERÊNCIAS}

AlBuQUERQUE, G. C. A.; CÂNDIDO, G. A. Capital social e desenvolvimento no submédio São Francisco. In: Gestão sustentável dos recursos naturais: uma abordagem participativa [online]. Campina Grande: EDUEPB, pp. 123-147, 2013.

ALLEN, R. G.; PEREIRA, L. S.; RAES, D.; SMITH, M. Crop evapotranspiration - guidelines for computing crop water requirements. Rome: FAO, Irrigation and Drainage Paper: 56, 300p., 1998.

ALMEIDA, H.A; SILVA, L Determinação das características hídricas da microbacia de drenagem da barragem Vaca Brava. Revista Brasileira de Agrometeorologia, v.16, n.1, p.77-86, 2008. 
Articulação do Semiárido (ASA). Brasil. Disponível em: http://www.asabrasil.org.br/. Acessado em 20/12/2015.

CAMARGO, A. P.; SENTELHAS, P. C. Avaliação do desempenho de diferentes métodos de estimativa da evapotranspiração potencial no estado de São Paulo, Brasil. Revista Brasileira de Agrometeorologia, Santa Maria, v. 5, n. 1, 1997.

CORREIA, R.C.; ARAÚJO, J. L. P.; BARROS CAVALCANTI, E. A Fruticultura como vetor de desenvolvimento: o caso dos municípios de Petrolina (PE) e Juazeiro (BA). In: XXXVIII Congresso Brasileiro de Economia e Sociologia Rural. Anais. Recife, PE. 2001.

COSTA, R. L.; DOS SANTOS SILVA, F. D.; SARMANHO, G. F.; LUCIO, P. S. Imputação Multivariada de Dados Diários de Precipitação e Análise de Índices de Extremos Climáticos. Revista Brasileira de Geografia Física, Recife, v.5, n.3, p. 661-675, 2012.

CUNHA A, P.; ALVALÁ, R.; KUBOTA, P. Y.; VIEIRA, R. Impacts of land use and land cover changes on the climate over Northeast Brazil. Atmospheric Science Letters, v.16, n.3, 2015.

GRISMER, M. E.; ORANG, M.; SNYDER, R.; MATYAC, R. Pan evaporation to reference evapotranspiration conversion methods. Journal of Irrigation Drainage Engineering, New York, v. 128, n. 3, p. 180 - 184, 2002.

HARGREAVES, G. H.; SAMANI, Z. A. Reference crop evapotranspiration from temperature. Applied Engineering Agriculture, v.1, n.2, 1985.

HAN, S. J.; HU, H. P. Spatial variations and temporal changes in potential evaporation in the Tarim Basin, northwest China (1960-2006): influenced by irrigation? Hydrological Processes. V.26, 2102.

HATCH, U.; JAGTAP, S.; JONES, J.; LAMB, M. Potential effects of climate change on agricultural water use in the southeast U.S. Journal of the American Water Resources Association, v. 35, 1999.

JHAJHARIA, D.; KUMAR, R.; DABRAL, P. P.; SINGH, V. P.; CHOUDHARY, R. R.; DINPASHOH, Y. Reference evapotranspiration under changing climate over the Thar Desert in India. Meteorological Applications, v. 22, 2015.

LACERDA, M.A.D.; LACERDA, R.D. O cluster da fruticultura no Pólo Petrolina/ Juazeiro, Revista de Biologia e Ciências da Terra, v.4, n.01, Campina Grande, PB, 2004.

LINACRE, E.T. A simple formula for estimating evapotranspiration rates in various climates, using temperature data alone. Agric. Meteorology, v.18, 1977.

MENDONÇA, E. A.; DANTAS, R. T. Estimativa da evapotranspiração de referência no município de Capim, PB. Revista Brasileira de Engenharia Agrícola e Ambiental, v.14, p.196-202, 2010.

MOURA, A. R. C.; MONTENEGRO, S. M. G. L.; ANTONINO, A. C. D.; AZEVEDO, J. R. G. de.; SILVA, B. B. da; OLIVEIRA, L. M. M. de.; Evapotranspiração de referência baseada 
em métodos empíricos em bacia experimental no estado de Pernambuco - Brasil. Revista Brasileira de Meteorologia, v.28, n.2, p. 181 - 191, 2013.

MURRAY, F. W. On the computation of saturation vapor pressure. Journal of Applied Meteorology, v.6, p.203-204. 1967.

NAM, W. H.; HONG, E. M.; CHOI, J. Y. Has climate change already affected the spatial distribution and temporal trends of reference evapotranspiration in South Korea? Agricultural Water Management, v.150, 2015.

OCDE/FAO - Organização Para A Cooperação E Desenvolvimento Econômico. Perspectivas Agrícolas no Brasil: desafios da agricultura brasileira 2015-2024. Disponível em: https://www.fao.org.br/download/PA20142015CB.pdf. Acesso em: 20/02/2017.

OLIVEIRA, L. F. C. de; CARVALHO, D. F. de; ROMÃO, P. A.; CORTÊS, F. C. Estudo comparativo de modelos de estimativa da evapotranspiração de referência para algumas localidades no Estado de Goiás e Distrito Federal. Pesquisa Agropecuária Tropical, Goiânia, v.31, n.2, p.121-126, 2001.

OLIVEIRA, L. M. M. DE; MONTENEGRO, S. M. G. L.; AZEVEDO, J. R. G. DE; SANTOS, F. X. Evapotranspiração de referência na bacia experimental do riacho Gameleira, PE, utilizando-se lisímetro e métodos indiretos. Revista Brasileira de Ciências Agrárias, v.3, n.1, p.58-67, 2008.

PEREIRA, A. R.; NOVA, N. A. V.; PEREIRA, A. S.; BARBIERI, V. A model for class-A pan coefficient. Agricultural and Forest Meteorology, Amsterdam, v. 76, n.1, 1995.

SHAN, N.; SHI, Z.; YANG, X.; GAO, J.; CAI, D. Spatiotemporal trends of reference evapotranspiration and its driving factors in the Beijing-Tianjin Sand Source Control Project Region, China. Agricultural and Forest Meteorology, v.200, 2015.

SILVA, M. T. Zoneamento de risco climático para a cultura do amendoim no estado do Rio Grande do Norte. Revista de Biologia e Ciências da Terra, v.7, n.2, 2007.

SIlVA, H. C. D.; SILVA, M. T.; SIlvA, M. M. M. A.; ROCHA JUNIOR, C. A. N. Comparação entre métodos de estimativa da Evapotranspiração de Referência (ETo) na região de Petrolina-PE. Ciência e Natura, Santa Maria, v. 36 Ed. Especial II, p. 456-461 2014.

SNYDER, R. L. Equation for evaporation pan to evapotranspiration conversion. Journal of Irrigation and Drainage Enginnering of ASCE, New York, v. 118, n. 6, 1992.

SOUSA, I. F. et al. Evapotranspiração de referência nos perímetros irrigados do Estado de Sergipe. Revista Brasileira de Engenharia Agrícola e Ambiental, Campina Grande, v. 14, n. $6,2010$.

TAGLIAFERRE, C.; NETO, I. J. S.; COTRIM, C. E.; COSTA, H. A.; SANTOS, L. C.; BARROSO; NILSON I. S.; GUIMARÃES, D. U. G. Uso do irrigâmetro na estimativa da evapotranspiração de referência para o município de Guanambi-BA. In: Congresso Brasileiro De Agrometeorologia, XVII, Trabalho completo, Guarapari, SBA, CD-ROOM. GuarapariES, 2011. 
TAGLIAFERRE, C.; SILVA, R. A. J.; ROCHA, F. A.; SANTOS, L. C.; SILVA, C. S. Estudo comparativo de diferentes metodologias para determinação da evapotranspiração de referência em Eunápolis-BA. Revista Caatinga, Mossoró, v. 23, n. 1, p. 103-111, 2010.

TEIXEIRA, A. H. C. Water productivity assessments from field to large scale: a case study in the Brazilian semi-arid region. Saarbrücken: Lambert Academic Publishing, 2009.

TEIXEIRA, A. H. C. Informações agrometeorológicas do polo Petrolina, PE/ Juazeiro, BA - 1963 a 2009. Petrolina: Embrapa Semiárido, Documentos, n.233, 2010.

VAN BUUREN, S.; GROOTHUIS-OUDSHOORN, K. MICE: Multivariate Imputation by Chained Equations in R. Journal of Statistical Software, vol. 45, n.3, p. 1-67, 2011.

VIANELlO, R. L.; ALVES, A. R. Meteorologia: básica e aplicações. 2. Ed. Viçosa, MG: Ed. UFV. 460p. 2012.

WILlMOTT, C. J., ACKLESON, S. G., DAVIS, R. E., FEDDEMA, J. J., KLINK, K. M.,. LEGATES, D. R., O'DONNELL, J., ROWE, C. M. Statistics for the evaluation and comparison of models. Journal of Geophysical Research Oceans, Washington, vol. 90, n.C5, p. 8995-9005, 1985.

\section{AGRADECIMENTOS}

Os autores agradecem a EMBRAPA Semiárido por disponibilizar os dados meteorológicos. O primeiro autor agradece ao Programa de Pós-Graduação em Ciências Climáticas da Universidade Federal do Rio Grande do Norte (PPGCC-UFRN) pelo incentivo à pesquisa e a Coordenação de Aperfeiçoamento de Pessoal de Nível Superior (CAPES) pela concessão de bolsa durante o Mestrado.

Recebido em: 28/08/2017

Aceito para publicação em: 31/10/2017 